\title{
Hydroxyurea Use in Children with Sickle Cell Disease: Do Severely Affected Patients Use It and Does It Impact Hospitalization Outcomes?
}

\author{
Susan E. Creary, MD, MSc ${ }^{1,{ }^{*}}$, Deena J. Chisolm, PhD ${ }^{1}$, Terah L. Koch, MPH ${ }^{1}$, Victoria A. \\ Zigmont, $\mathrm{MPH}^{2}$, Bo Lu, $\mathrm{PhD}^{3}$, and Sarah H. O'Brien, MD, MSc ${ }^{1}$ \\ ${ }^{1}$ Nationwide Children's Hospital, The Ohio State University, Columbus, $\mathrm{OH}$ \\ ${ }^{2}$ The Ohio State University, College of Public Health, Division of Epidemiology, Columbus, $\mathrm{OH}$ \\ ${ }^{3}$ The Ohio State University, College of Public Health, Division of Biostatistics, Columbus, $\mathrm{OH}$
}

\section{Abstract}

\begin{abstract}
Background-Expert guidelines recommend that hydroxyurea (HU) be offered to all children with Hemoglobin SS and $\mathrm{S} \beta^{0}$ sickle cell disease (SCD) and be considered for children with clinically severe Hemoglobin SC or S $\beta^{+}$. This study aims to determine the rate of $\mathrm{HU}$ use in hospitalized children, if $\mathrm{HU}$ is differentially used in children with clinically severe SCD, and if HU users have shorter lengths of stay (LOS), fewer intensive care unit (ICU) admissions, and fewer inpatient transfusions compared to non-users.
\end{abstract}

Procedure-Using the Pediatric Health Information System, we performed a retrospective analysis of children ages 2-18 years with SCD discharged between January 1, 2011-September 30,2014 . We defined patients as having clinically severe SCD if they had a recent ICU admission or $\geq 3$ admissions in the preceding year.

Results-Of the 2,665 unique children identified, approximately $80 \%$ had an inpatient code indicating HU use. Significantly more $(\mathrm{p}<0.001)$ non-users $(30.1 \%)$ had a recent ICU admission compared to HU users (18.7\%). More non-users (33.9\%) had a history of $\geq 3$ admissions compared to HU users $(21.5 \%)(\mathrm{p}<0.001)$. After applying propensity score weighting, the groups did not differ in their LOS, prevalence of ICU admissions, or prevalence of transfusions.

Conclusion-HU use is high among hospitalized children with SCD. However, HU is not utilized by many children with clinically severe SCD. These results support that HU be considered in children with SCD to prevent hospitalization rather than as a treatment to improve hospitalization outcomes.

\footnotetext{
*Correspondence to: Susan E. Creary, MD, MSc, Division of Pediatric Hematology and Oncology, Nationwide Children's Hospital, 700 Children's Drive, Columbus, OH 43205, susan.creary@ nationwidechildrens.org, Phone: 614-722-3569.

Conflicts of Interest

The authors have neither received payment to produce this manuscript nor have conflicts of interest to disclose.
} 


\section{INTRODUCTION}

Hydroxyurea (HU) is the only disease modifying medication available for children with sickle cell disease (SCD). Multiple clinical trials show that HU reduces vaso-occlusive pain, acute chest syndrome (ACS) episodes, hospitalizations, and erythrocyte transfusions in pediatric patients. [1-3] Retrospective data also suggest that HU reduces mortality in children with SCD because it results in fewer deaths from ACS episodes and infection.[4] These findings led to the 2014 National Heart, Lung, and Blood Institute Expert Panel Report's recommendation that $\mathrm{HU}$ be offered to all children with Hemoglobin SS and $\mathrm{S} \beta^{0}$ sickle cell disease (SCD) and be considered for children with Hemoglobin SC and $\mathrm{S} \beta^{+} \mathrm{SCD}$ who have clinically severe SCD.[5]

Epidemiology data show that since HU's Food and Drug Administration approval in 1998, hospitalization lengths of stay (LOS) for all children and adults with SCD are significantly shorter, [6] but HU's impact on hospitalized children is unknown. A cost analysis from the BABYHUG clinical trial showed that children who took HU had reduced inpatient costs compared to children taking placebo, but it was unclear if this was because HU prevented hospitalizations or because it reduced the severity of inpatient illnesses.[7] Describing current HU use among hospitalized children with SCD could identify whether HU is being prescribed to children who may benefit from it and whether HU improves hospitalization outcomes.

In this study we aim to determine the current rate of $\mathrm{HU}$ use in hospitalized children and to determine if $\mathrm{HU}$ is differentially used in children with clinically severe SCD. Additionally, we will examine if hospitalized HU users have improved hospitalization outcomes as measured by fewer deaths, shorter lengths of stay (LOS), fewer intensive care unit (ICU) admissions, and fewer erythrocyte transfusions compared to HU non-users.

\section{METHODS}

\section{Study Design and Database}

We performed a retrospective analysis of the Pediatric Health Information System (PHIS) inpatient data, a database developed by the Children's Hospital Association. PHIS contains comprehensive clinical and financial data submitted from over 48 Children's Hospital Association member hospitals. Participating PHIS hospitals are among the largest and most advanced children's hospitals in America. Data within PHIS undergo reliability and validity checks prior to inclusion into the database. Patients are de-identified but are coded with unique medical identification numbers to allow individual patients to be followed over time. Nationwide Children's Hospital Institutional Review Board granted exempt status to our use of de-identified data and a PHIS external release was obtained.

\section{Population}

Children ages 2-18 years with SCD discharged between January 1, 2011-September 30, 2014 from the 42 hospitals within PHIS that provided complete clinical and financial data were included in the analyses. Only patients' most recent hospitalization during the study period was analyzed to reflect the current rate of HU use. Since children with SCD with an 
acute stroke typically require prolonged hospitalizations, ICU admission, receive erythrocyte transfusion and because $\mathrm{HU}$ is not a proven therapy for stroke prevention,[8] we excluded admissions that contained an International Classification of Diseases, Ninth Revision, Clinical Modification (ICD-9-CM) diagnosis for stroke (434.00-434.11, 434.90, 434.91, 438).

\section{Data Collection}

The following patient data within PHIS were obtained for all eligible discharges: age, gender, HU use, discharge status (dead, alive), ICU admission, asthma diagnosis, total number of ICD-9-CM diagnoses, LOS (days), erythrocyte transfusion, and insurance provider (private, public, unknown). We considered patients to be HU users if their hospitalization data contained the Pharmacy Current Procedural Terminology code for HU (171927). Since the ICD-9-CM codes for SCD genotype are not discreet, we did not use SCD genotype in our analyses. Instead, we defined patients as having clinically severe SCD if they had a history of a recent ICU admission (after 2009) or a history of $\geq 3$ hospital admissions in the year preceding their most recent admission. This severity definition was selected because it is used in clinical practice and in clinical trials [3,9] to identify children with severe SCD and because it could be captured within PHIS.

\section{Statistical Analyses}

Descriptive statistics were used for independent variables in our study cohort. For continuous variables (age, number of diagnoses) we performed t-tests. We used Chi-Square tests to compare categorical variables (gender, asthma diagnosis, ICU history, inpatient admission history, and insurance) across exposure categories (HU users and non-users). Ttests and Chi-Squared tests were performed before and after applying propensity score weighting.

Propensity scores can be used to reduce bias in observational studies when the baseline characteristics of the study groups that are being compared are different.[10,11] Propensity score weighting is a statistical method that can be applied when the baseline covariates between groups are not balanced. Propensity score weighting was used instead of matching to avoid discarding HU users' hospitalization data. In this study, weights in the HU-user group were defined as (1/probability of being in the HU-user group) and as (1/probability of being in the non-user group) for the non-user group. Patient age, gender, co-existent asthma diagnosis, recent ICU admission, total number of ICD-9-CM diagnoses for analyzed admission, three or more admissions in the prior year, and primary insurance were included in the propensity weights. Three outcomes were used to compare HU users and non-users after applying propensity weights: (1) a Poisson regression to model the average LOS, (2) a logistic regression to model the prevalence of being admitted to the ICU, and (3) a logistic regression to model the prevalence of being given an erythrocyte transfusion. The “Treatment Effects" program was implemented using Stata, version 14.0 (StataCorp®, LP). This program simultaneously estimates propensity scores and the outcome model. 


\section{RESULTS \\ Clinical Characteristics}

We identified 2,665 unique children with SCD, after excluding one HU user with missing gender information. Approximately $80 \%$ of the children had an inpatient code indicating that they were prescribed HU during their admission. Most of the study cohort was coded as having Hemoglobin SS SCD (Table I). Six patients died during hospitalization, two HU users and four non-users.

HU users differed in their baseline characteristics compared to non-users. After propensity score weighting balanced these covariates, HU users and non-users were similar across all covariates (Table II).

\section{Severity of IIIness}

Admission to the ICU—During the study period, 146 (5.5\%) patients required care in the ICU. After applying propensity weighting, $\mathrm{HU}$ users had a 1.3\% higher prevalence of being admitted to the ICU compared to non-users (95\% CI: $-0.0034,0.0289)$, but this difference was not statistically significant.

Erythrocyte transfusion-In the entire cohort, 668 (25.1\%) of the patients received at least one erythrocyte transfusion. After applying propensity weighting, there was a $1.9 \%$ lower prevalence of receiving an erythrocyte transfusion among HU users (95\% CI: $-0.0628,0.253$ ) compared to non-users, but this difference was not statistically significant.

LOS-The average LOS for the entire cohort was 4.23 days ( $\mathrm{SD} \pm 7.18$ days). After propensity weighting, HU users had a longer average LOS (4.01 days, 95\% CI: 3.8404, 4.1721) compared to non-users ( 4.18 days, $95 \%$ CI: 3.6985 , 4.6663), but this difference was not statistically significant.

\section{DISCUSSION}

Our study confirms that HU use is high among hospitalized children with SCD. Interestingly, we found that $30 \%$ of patients with a recent ICU admission and 33\% of patients with a history of at least 3 admissions did not use HU, despite few other available disease modifying therapies. It is possible that some non-users were receiving chronic transfusion therapy instead of $\mathrm{HU}$ to treat their SCD, but we suspect that this occurred in only a few patients, since patients with a history of stroke, one of the common indications for chronic transfusion therapy, were excluded. Furthermore, we queried a subset of PHIS data and identified that $<5 \%$ of $\mathrm{HU}$ non-users meeting our eligibility criteria received $\geq 7$ transfusions during the study period. This suggests that $\mathrm{HU}$ may be worth stronger consideration in children with clinically severe $\mathrm{SCD}$, as $\mathrm{HU}$ is proven to prevent hospitalization in children with clinically severe SCD [3,9] and because hospitalization is a risk factor for developing other complications, such as ACS.[12]

There is increasing interest in exploring HU's anti-inflammatory properties and then using $\mathrm{HU}$ as an anti-inflammatory agent in the acute setting for patients with SCD.[13] Our results 
suggest that HU use does not significantly impact the severity of illness in hospitalized children. This may be because HU's primary mechanism of action is to induce fetal hemoglobin production [2] and this process can take many months to prevent vaso-occlusive pain and ACS episodes.[14] Further investigation is needed to determine if increased HU dosing or intravenous $\mathrm{HU}$ administration may be able to achieve an anti-inflammatory effect that is sufficient to result in improved hospitalization outcomes.[15] Currently, erythrocyte transfusion remains the only therapy available that rapidly reduces the percentage of sickled erythrocytes to impact the severity of illness in hospitalized patients.[16,17] Since supportive care interventions (e.g. incentive spirometry) reduce secondary complications in hospitalized patients that result in longer LOS, $[18,19]$ interventions that optimize these supportive care therapies may also be another way to reduce LOS, ICU admissions, and erythrocyte transfusions in children with SCD until novel interventions are developed and tested.

A limitation of our study is the potential for coding errors,[20] since PHIS uses ICD-9-CM and other billing codes to identify outcomes in hospitalized patients. We specifically did not use patients' coded SCD genotype in our propensity score weighting. The ability of these codes to accurately identify patients' SCD genotype or disease severity is not known, but likely unreliable, because the ICD-9-CM codes for the SCD genotypes are not discreet and inappropriately group patients together. For example, the ICD-9-CM codes for Hemoglobin S- $\beta$ Thalassemia $(282.41,282.42)$ do not distinguish between Hemoglobin $\mathrm{S} \beta^{+}$and Hemoglobin $S \beta^{0}$ SCD, even though patients with Hemoglobin $S \beta^{0}$ SCD have more severe SCD than patients with Hemoglobin $\mathrm{S}^{+}$.[4] To limit these potential errors from impacting our comparisons, we used variables that have more straightforward ICD-9-CM coding. It is also important to note that we were not able to determine if patients may have initiated HU during their hospitalization or if some patients may have had their HU held or mistakenly not ordered during their entire hospitalization. Since HU is not a proven treatment from complications in the acute setting and because $80 \%$ of the cohort was prescribed $\mathrm{HU}$ at some point during their hospitalization, we suspect that $\mathrm{HU}$ was not frequently initiated or held completely during patients' hospitalizations.

We also note there are few limitations when applying propensity score weighting. First, it does not eliminate the potential for unmeasured confounding. Second, it assumes that there is a constant treatment effect over the course of the study.[21] Since PHIS does not contain information about patients' HU dose, adherence, duration of therapy, or hematologic response and because these are all potential factors that may modify HU's effect on patients over time, we were unable to evaluate if $\mathrm{HU}$ had a constant effect.[9,22,23]

In summary, we report that hospitalized children with SCD frequently use HU. However, HU is not utilized by many children with clinically severe SCD who have limited other treatment options. Our results support consideration of HU in children with SCD to prevent their hospitalization, rather than as a treatment to improve their hospitalization outcomes. To improve the care of hospitalized children with SCD, additional treatments are needed to reduce their LOS, ICU admissions, and need for erythrocyte transfusions. 


\section{Abbreviations}
HU
Hydroxyurea
SCD
Sickle cell disease
LOS
Length of stay
ICU
Intensive care unit
ACS
Acute chest syndrome
PHIS
Pediatric Health Information System
ICD-9-CM
International Classification of Diseases, Ninth Revision, Clinical
Modification

\section{References}

1. Hankins JS, Ware RE, Rogers ZR, Wynn LW, Lane PA, Scott JP, Wang WC. Long-term hydroxyurea therapy for infants with sickle cell anemia: the HUSOFT extension study. Blood. 2005; 106:2269-2275. [PubMed: 16172253]

2. Wang WC, Ware RE, Miller ST, Iyer RV, Casella JF, Minniti CP, Rana S, Thornburg CD, Rogers ZR, Kalpatthi RV, Barredo JC, Brown RC, Sarnaik SA, Howard TH, Wynn LW, Kutlar A, Armstrong FD, Files BA, Goldsmith JC, Waclawiw MA, Huang X, Thompson BW. BABY HUG investigators. Hydroxycarbamide in very young children with sickle-cell anaemia: a multicentre, randomised, controlled trial (BABY HUG). Lancet. 2011; 377:1663-1672. [PubMed: 21571150]

3. Kinney TR, Helms RW, O’Branski EE, Ohene-Frempong K, Wang W, Daeschner C, Vichinsky E, Redding-Lallinger R, Gee B, Platt OS, Ware RE. Safety of hydroxyurea in child with sickle cell anemia: results of the HUG-KIDS study, a phase I/II trial. Pediatric Hydroxyurea Group. Blood. 1999; 94:1550-1554. [PubMed: 10477679]

4. Lobo CL, Pinto JF, Nascimento EM, Moura PG, Cardoso GP, Hankins JS. The effect of hydroxcarbamide therapy on survival of children with sickle cell disease. Br J Haematol. 2013; 161:852-860. [PubMed: 23590693]

5. Yawn BP, Buchanan GR, Afenyi-Annan AN, Ballas SK, Hassell KL, James AH, Jordan L, Lanzkron SM, Lottenberg R, Savage WJ, Tanabe PJ, Ware RE, Murad MH, Goldsmith JC, Ortiz E, Fulwood R, Horton A, John-Sowah J. Management of sickle cell disease: summary of the 2014 evidence-based report by expert panel members. JAMA. 2014; 312:1033-1048. [PubMed: 25203083]

6. Okam MM, Shaykevich S, Ebert BL, Zaslavsky AM, Ayanian JZ. National trends in hospitalizations for sickle cell disease in the United States following the FDA approval of hydroxyurea, 1998-2008. Med Care. 2014; 52:612-618. [PubMed: 24926708]

7. Wang WC, Oyeku SO, Luo Z, Boulet SL, Miller ST, Casella JF, Fish B, Thompson BW, Grosse SD. BABY HUG Investigators. BABY HUG Investigators. Hydroxyurea is associated with lower costs of care of young children with sickle cell anemia. Pediatrics. 2013; 132:677-683. [PubMed: 23999955]

8. Kassim AA, Galadanci NA, Pruthi S, DeBaun MR. How I treat and manage strokes in sickle cell disease. Blood. 2015; 125:3401-3410. [PubMed: 25824688]

9. Charache S, Terrin ML, Moore RD, Dover GJ, Barton FB, Eckert SV, McMahon RP, Bonds DR. Effect of hydroxyurea on the frequency of painful crises in sickle cell anemia. Investigators of the Multicenter Study of Hydroxyurea in Sickle Cell Anemia. N Engl J Med. 1995; 332:1317-1322. [PubMed: 7715639]

10. Rosenbaum PR, Rubin DB. The central role of the propensity score in observational studies for causal effects. Biometrika. 1983; 70:41-55.

11. Robins JM, Hernan MA, Brumback B. Marginal structural models and causal inference in epidemiology. Epidemiology. 2000; 11:550-560. [PubMed: 10955408] 
12. Vichinsky EP, Neumayr LD, Earles AN, Williams R, Lennette ET, Dean D, Nickerson B, Orringer E, McKie V, Bellevue R, Daeschner C, Manci EA. Causes and outcomes of the acute chest syndrome in sickle cell disease. National Acute Chest Syndrome Study Group. N Engl J Med. 2000; 342:1855-1865. [PubMed: 10861320]

13. Almeida CB, Souza LE, Leonardo FC, Costa FT, Werneck CC, Covas DT, Costa FF, Conran N. Acute hemolytic vascular inflammatory processes are prevented by nitric oxide replacement or a single dose of hydroxyurea. Blood. 2015; 126:711-720. [PubMed: 26019278]

14. Ware RE. How I use hydroxyurea to treat young patients with sickle cell anemia. Blood. 2010; 115:5300-5311. [PubMed: 20223921]

15. Gladwin MT. Revisiting the hyperhemolysis paradigm. Blood. 2015; 126:695-696. [PubMed: 26251222]

16. Adams R, McKie V, Hsu L, Files B, Vichinsky E, Pegelow C, Abboud M, Gallagher D, Kutlar A, Nichols FT, Bonds DR, Brambilla D. Prevention of a first stroke by transfusion in children with abnormal results of transcranial Doppler ultrasonography. N Engl J Med. 1998; 339:5-11. [PubMed: 9647873]

17. Saylors RL, Watkins B, Saccente S, Tang X. Comparison of automated red cell exchange transfusion and simple transfusion for the treatment of children with sickle cell disease acute chest syndrome. Pediatr Blood Cancer. 2013; 60:1952-1956. [PubMed: 24000077]

18. Ahmad FA, Macias CG, Allen JY. The use of incentive spirometry in pediatric patients with sickle cell disease to reduce the incidence of acute chest syndrome. J Pediatr Hematol Oncol. 2011; 33:415-420. [PubMed: 21792036]

19. Merrill WW. Incentive spirometry in sickle cell crisis. N Engl J Med. 1996; 334:124-125. [PubMed: 8531956]

20. O’Malley KJ, Cook KF, Price MD, Wildes KR, Hurdle JF, Ashton CM. Measuring Diagnoses: ICD Code Accuracy. Health Serv Res. 2005; 40:1620-1639. [PubMed: 16178999]

21. Hernán MA, Brumback B, Robins JM. Marginal structural models to estimate the causal effect of zidovudine on the survival of HIV-positive men. Epidemiology. 2000; 11:561-570. [PubMed: 10955409]

22. Candrilli SD, O'Brien SH, Ware RE, Nahata MC, Seiber EE, Balkrishnan R. Hydroxyurea adherence and associated outcomes among Medicaid enrollees with sickle cell disease. Am J Hematol. 2011; 86:273-277. [PubMed: 21328441]

23. Zimmerman SA, Schultz WH, Davis JS, Pickens CV, Mortier NA, Howard TA, Ware RE. Sustained long-term hematologic efficacy of hydroxyurea at maximum tolerated dose in children with sickle cell disease. Blood. 2004; 103:2039-2045. [PubMed: 14630791] 


\section{Table I}

Patients' HU Use By ICD-9-CM Coded SCD Genotype

\begin{tabular}{|l|c|c|c|c|}
\hline SCD Genotype & ICD-9-CM Codes & $\begin{array}{c}\text { Patients n=2,665 (\% of total } \\
\text { patients) }\end{array}$ & $\begin{array}{c}\text { HU-Users n=2,166 (\% of } \\
\text { genotype) }\end{array}$ & $\begin{array}{c}\text { Non-Users n=499 (\% of } \\
\text { genotype) }\end{array}$ \\
\hline SS & 282.61 & $2,225(83.5)$ & $1,820(81.8)$ & $405(18.2)$ \\
\hline S $\beta$ Thalassemia & 282.62 & $190(7.1)$ & $160(84.2)$ & $30(15.8)$ \\
\hline SC & 282.41 & $116(4.4)$ & $76(65.5)$ & $40(34.5)$ \\
\hline Unspecified & 282.63 & $134(5.0)$ & $110(82.1)$ & $24(17.9)$ \\
\hline
\end{tabular}

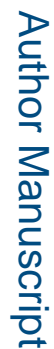

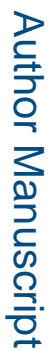

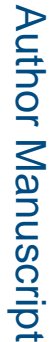


